\title{
Modul Elektronik Berbasis Problem Solving Berdasarkan Hasil Penelitian Aktivitas Immunostimulan pada Tikus Diabetes Melitus Tipe II
}

\author{
Ulfa Maulida Farid ${ }^{1}$, Abdul Gofur ${ }^{1}$, Sri Rahayu Lestari ${ }^{1}$ \\ 'Pendidikan Biologi-Universitas Negeri Malang
}

\begin{tabular}{l}
\hline \hline INFO ARTIKEL \\
\hline Riwayat Artikel: \\
Diterima: 03-05-2019 \\
Disetujui: 29-05-2019 \\
\hline
\end{tabular}

Kata kunci:

electronic module; problem solving; critical thinking; modul elektronik; problem solving; berpikir kritis

Alamat Korespondensi:
Ulfa Maulida Farid
Pendidikan Biologi
Universitas Negeri Malang
Jalan Semarang 5 Malang
E-mail: ulfaku.maulida@gmail.com

\begin{abstract}
ABSTRAK
Abstract: This research was aimed to produce electronic modules Problem Solving based of research immunostimulant activity in type 2 diabetes melitus rats to improve students' critical thinking skills that are valid, practical and efficient. This study use ADDIE. results the media expert validation obtained a percentage of $92.74 \%$ is valid. material expert validation obtained a percentage of $92.85 \%$ with a very valid category. The overall validation results from field practitioners received a percentage of $93.92 \%$ with valid category. In terms of readability and practicality gained a percentage of $83.31 \%$.

Abstrak: Penelitian ini bertujuan untuk menghasilkan modul elektronik pemecahan masalah berdasarkan aktivitas imunostimulan penelitian pada tikus diabetes melitus tipe II untuk meningkatkan keterampilan berpikir kritis siswa yang valid, praktis dan efisien. Penelitian ini menggunakan ADDIE. Hasil validasi ahli media diperoleh persentase 92,74\% valid. Validasi ahli materi diperoleh persentase 92,85\% dengan kategori sangat valid. Keseluruhan hasil validasi dari praktisi lapangan menerima persentase 93,92\% dengan kategori valid. Dalam hal keterbacaan dan kepraktisan diperoleh persentase $83,31 \%$.
\end{abstract}

Perguruan tinggi sebagai penyelenggara pendidikan merupakan salah satu wadah untuk mengembangkan ilmu pengetahuan dan teknologi (Depdikbud, 2012). Pembelajaran di pendidikan tinggi mengacu pada kurikulum program sarjana mampu memanfaatkan ilmu pengetahuan, teknologi, dan seni serta mengaplikasikan bidang keahlian dalam adaptasi dan memecahkan masalah (Dirjendikti, 2014). Hasil observasi pada 32 mahasiswa yang belum dan sudah menempuh matakuliah anatomi fisiologi manusia S1 pendidikan Biologi UMM pada tanggal 20 Mei 2018 menunjukkan bahwa sistem imun termasuk materi sulit. Alasan kesulitan pada sistem imun yaitu materi bersifat abstrak (20\%), materi sistem imun merupakan materi yang kompleks (25\%), sulit mengaplikasikan materi sistem imun dalam kehidupan nyata (28\%), dan kurang ketersediaan bahan ajar yang relevan dan mudah diaplikasikan dalam kehidupa nyata (27\%). Hasil belajar mahasiswa menunjukkan kurangnya kemampuan berpikir kritis. kemampuan berpikir kritis dianalisis melalui hasil observasi terhadap soal tes yang mana belum menampilkan aspek dalam mengukur kemampuan berpikir kritis. Selain itu, sistem imun menggunakan metode ceramah dan pemberian handout dari dosen.

Kegiatan praktikum terkait materi sistem imun sampai saat ini belum pernah dilakukan. Materi sistem imun di program studi Pendidikan Biologi UMM digabungkan dengan materi sistem kardiovaskuler, sedangkan alokasi waktu hanya 3 sks di dalam RPS. Dosen hanya menjelaskan sedikit dan mahasiswa diminta mempelajari secara mandiri melalui file power point. Bahan ajar yang mengembangkan kemampuan berpikir kritis mahasiswa sangat diperlukan. Bahan ajar yang menarik ialah modul elektronik (Montagnes, 2000). Pemanfaatan modul yang dipadukan dengan teknologi informasi merupakan penggabungan pembelajaran yang dapat membantu mahasiswa belajar lebih efektif meningkatkan hasil belajar (Carey, 2010), motivasi belajar (Halidi, \& Sahrul, 2015), kreativitas (Sarianti, 2016), kemandirian mahasiswa, kolaboratif dan meningkatkan kemampuan berpikir kritis (Aminatun et al., 2016; Krnel \& Bajd, 2009; Raharjo, Suryati, \& Khery, 2017). Modul elektronik yang dikembangkan berorientasi model pembelajaran pemecahan masalah. Problem solving adalah sarana menggunakan pengetahuan, keterampilan, dan pemahaman yang diperoleh sebelumnya pada situasi baru dan berbeda (Krulik \& Rudnick, 1987). 
Pengembangan modul elektronik berbasis Problem solving pada sistem imun dapat mengembangkan kemampuan berpikir kritis. Berpikir kritis merupakan keterampilan dalam mengajukan pertanyaan dan mendefinisikan suatu permasalahan atau mencari cara yang paling tepat untuk memecahkan suatu masalah (Ennis, 2011). Berdasarkan latar belakang tersebut, peneliti mengembangkan modul elektronik berbasis Problem solving pada materi sistem imun bertujuan agar dapat meningkatkan kemampuan berpikir kritis. Modul dikembangkan berdasarkan hasil penelitian aktivitas immune stimulan pada tikus model diabetes melitus tipe II.

\section{METODE}

Penelitian pengembangan ini menggunakan model pengembangan ADDIE yang terdiri atas lima tahap, yaitu Analyze, Design, Develop, Implement, dan Evaluate (Branch, 2009). Tahap penelitian dibatasi hanya sampai pada Develop. Tahap Analyze dilakukan dengan pemberian angket analisis kebutuhan bahan ajar kepada satu dosen pengampu dan mahasiswa yang telah menempuh matakuliah anatomi fisiologi manusia sebanyak 32 mahasiswa SI Biologi Universitas Muhammadiyah Malang. Tahap Design dilakukan dengan mendaftar semua komponen yang dibutuhkan dalam pengembangan modul elektronik berupa materi tentang sistem imun, menyusun rancangan produk, dan menyusun instrumen penilaian produk. Tahap Develop dilakukan untuk menghasilkan produk sesuai dengan rancangan, melakukan revisi formatif setelah dinilai kelayakan atau validasi oleh ahli media yaitu Rifka Fachrunnisa, S.Pd. M.Ed. Validator materi yaitu Nurwidodo, M.Pd. Validasi praktisi lapangan dilakukan oleh Dr. Nurul Mahmudati, M.kes, dan melakukan uji coba dalam skala kecil kepada mahasiswa S1 Biologi yang berjumlah 20 orang untuk melakukan uji keterbacaan sehingga akan diperolah data kepraktisan dari modul elektronik berbasis Problem Solving pada materi sistem imun yang telah dikembangkan. Data kuantitatif yaitu hasil validasi dan data kualitatif berupa saran serta komentar dari validator.

\section{HASIL}

Produk yang dihasilkan berupa modul elektronik berbasis Problem solving berdasarkan hasil penelitian aktivitas immunostimulan pada tikus diabetes melitus tipe II untuk meningkatkan kemampuan berpikir kritis. Modul elektronik berbasis Problem solving, meliputi tiga kegiatan belajar, yaitu sistem imun nonspesifik, sistem imun spesifik, dan kelainan fungsi sistem imun. Modul elektronik berbasis problem solving ini juga dilengkapi dengan sampul, kata pengantar, daftar isi, pendahuluan, kegiatan belajar, daftar rujukan, dan riwayat hidup. Berikut hasil validasi media, materi, praktisi lapangan, dan uji kepraktisan (Tabel 1-4).

\section{Validasi Ahli Media}

Tabel 1. Hasil Validasi Modul Elektronik Berbasis Problem Solving

\begin{tabular}{ccccccc}
\hline No & Aspek & Jumlah & Nilai Maksimal & Nilai Perolehan & Persentase (\%) & Kategori \\
\hline 1 & Ukuran sampul modul & 2 & 8 & 7 & 81,25 & Cukup valid \\
\hline 2 & Desain sampul modul & 9 & 36 & 32 & 88 & Sangat valid \\
\hline 3 & Desai nisi modul & 20 & 80 & 76 & 95 & Sangat valid \\
\hline \multicolumn{2}{c}{ Total } & & & 92,74 & Sangat valid \\
\hline
\end{tabular}

Hasil validasi modul elektronik berbasis problem solving oleh ahli media diperoleh $92.74 \%$ dan termasuk dalam kategori sangat valid. Desain sampul dan desain isi modul elektronik berbasis problem solving yang sudah dikembangkan dapat diimplementasikan.

\section{Validasi Ahli Materi}

Tabel 2. Hasil Validasi Modul Elektronik Berbasis Problem Solving

\begin{tabular}{clcccrc}
\hline No & Aspek yang dinilai & Jumlah & Nilai Maksimal & Perolehan & Persentase (\%) & Kategori \\
\hline 1 & Kelayakan Isi & 21 & 84 & 78 & 92,85 & Sangat valid \\
\hline 2 & Kelayakan penyajian & 12 & 48 & 43 & 89,58 & Sangat valid \\
\hline 3 & Penilaian Bahasa & 12 & 48 & 44 & 91,66 & Sangat valid \\
\hline 4 & Kelayakan Konten Soal & 12 & 60 & 55 & 91,66 & Sangat valid \\
\hline & Total & & & 91,43 & Sangat valid \\
\hline
\end{tabular}

Aspek yang dinilai pada validasi materi antara lain kesesuaian materi dengan capaian pembelajaran, keakuratan materi, pendukung materi pembelajaran, dan kemutakhiran materi. Berdasarkan hasil penilaian validitas materi pada modul elektronik berbasis problem solving diperoleh 91,43\% valid. Modul elektronik berbasis problem solving dapat digunakan dalam proses pembelajaran apabila memilki nilai validitas lebih dari 85,01\%, materi modul elektronik berbasis problem solving harus direvisi sesuai saran dan komentar validator sebelum implementasi di lapangan. 
Validasi Praktisi Lapangan

Tabel 3. Hasil Validasi oleh Praktisi Lapangan

\begin{tabular}{clccccc}
\hline No. & \multicolumn{1}{c}{ Aspek } & Jumlah & Maksimal & Perolehan & Persentase (\%) & Kategori \\
\hline 1 & Kelayakan bahasa & 7 & 35 & 30 & 85,71 & Sangat valid \\
\hline 2 & Kelayakan isi & 5 & 25 & 25 & 100 & Sangat valid \\
\hline 3 & Kelayakan penyajian & 10 & 50 & 45 & 90 & Sangat valid \\
\hline 4 & Karakteristik problem solving & 4 & 20 & 20 & 100 & Sangat valid \\
\hline \multicolumn{7}{r}{ Total } \\
\hline
\end{tabular}

Berdasarkan hasil validasi modul elektronik berbasis problem solving oleh praktisi lapangan yaitu 93,92\% sangat valid. Kategori tersebut menunjukkan secara keseluruhan modul elektronik berbasis problem solving yang telah dikembangkan dapat diaplikasikan dalam pembelajaran.

Uji Kepraktisan

Tabel 4. Data Respons Mahasiswa Kelas C Pendidikan Biologi terhadap Modul Elektronik Berbasis Problem Solving

\begin{tabular}{cccccc}
\hline No Mahasiswa & $\begin{array}{c}\text { Jumlah } \\
\text { Aspek }\end{array}$ & $\begin{array}{c}\text { Skor } \\
\text { Maksimal }\end{array}$ & $\begin{array}{c}\text { Skor } \\
\text { Perolehan }\end{array}$ & Persentase & $\begin{array}{c}\text { Kategori } \\
\text { Kelayakan }\end{array}$ \\
\hline Mahasiswa-1 & 17 & 85 & 73 & 85,88 & Sangat valid \\
Mahasiswa-2 & 17 & 85 & 65 & 76,47 & Valid \\
Mahasiswa-3 & 17 & 85 & 64 & 75,29 & Valid \\
Mahasiswa-4 & 17 & 85 & 72 & 84,71 & Valid \\
Mahasiswa-5 & 17 & 85 & 67 & 78,82 & Valid \\
Mahasiswa-6 & 17 & 85 & 68 & 80 & Valid \\
Mahasiswa-7 & 17 & 85 & 67 & 78,82 & Valid \\
Mahasiswa-8 & 17 & 85 & 66 & 77,65 & Valid \\
Mahasiswa-9 & 17 & 85 & 76 & 89,41 & Sangat Valid \\
Mahasiswa-10 & 17 & 85 & 69 & 81,17 & Valid \\
\hline & Jumlah & 850 & 840 & 80,9 & Valid
\end{tabular}

Berdasarkan data respons mahasiswa terhadap modul elektronik berbasis problem solving pada uji coba pendahuluan adalah 80,9\% dengan kategori valid. Hal tersebut menunjukkan Modul elektronik berbasis problem solving layak, namun perlu sedikit revisi sebelum digunakan untuk uji coba lapangan.

\section{PEMBAHASAN}

Produk modul elektronik berbasis problem solving untuk matakuliah anatomi fisiologi manusia di Universitas Muhammadiyah Malang. Modul elektronik berbasis problem solving yang dikembangkan terlebih dahulu dilakukan validasi kelemahan pada modul elektronik berbasis problem solving untuk digunakan sebagai perbaikan dan penyempurnaan modul elektronik (Belawati, 2003). Hasil revisi selanjutnya digunakan untuk uji pendahuluan pada mahasiswa S1 Pendidikan Biologi UMM.

Berdasarkan hasil validasi media oleh ahli media pada modul elektronik berbasis problem solving diperoleh hasil $92,74 \%$ sangat valid sehingga desain sampul, desain isi pada Modul elektronik berbasis problem solving yang dikembangkan dan dimplementasikan. Hasil validasi materi sebesar 91,43\% termasuk kategori sangat valid yang artinya modul elektronik berbasis problem solving dapat dimanfaatkan dalam proses belajar dengan sedikit revisi untuk implementasi di lapangan. Berdasarkan hasil validasi modul elektronik berbasis problem solving oleh praktisi lapangan diperoleh 93,92\% sangat valid, artinya keseluruhan modul elektronik berbasis problem solving dapat digunakan di lapangan.

Modul elektronik berbasis problem solving pada materi sistem imun ini merupakan sumber belajar tambahan untuk mahasiswa yang menempuh matakuliah anatomi fisiologi manusia. Modul elektroik yang dikembangkan memuat sintaks problem solving. Hal ini bertujuan untuk mempermudah mahasiswa memahami submateri sistemimun spesifik, sistem imun non spesifik dan kelainan fungsi sistem imun. Modul elektronik disusun dengan harapan agar mahasiswa mampu meningkatkan kemampuan berpikir kritis melalui proses pembelajaran problem solving materi sistem imun secara mandiri. Aspek kemampuan berpikir kritis yang dikembangkan yaitu Apply, evaluate, uses data to develope critical insight, analyze, synthesize (Greenstein, 2012). Modul elektronik berbasis Problem Solving diharapkan dapat memeberikan mahasiswa pengalaman belajar yang lebih bermakna, karena dikembangkan bertujuan untuk membantu mahasiswa belajar tentang masalah yang muncul dalam kehidupannya. Pembelajaran berbasis Problem Solving mampu meningkatkan kemampuan berpikir tingkat tinggi (Magsino, 2014), kemampuan berpikir kritis (Pradani, Zubaidah, \& Lestari, 2015; Suarsana \& Mahayukti, 2013; Sulistyaningkarti, Utami, \& Haryono, 2016). Selain itu, modul elektronik berbasis problem solving dikembangkan berdasarkan hasil penelitian pengaruh ekstrak tempe kedelai hitam terhadap kadar interleukin-6 pada tikus diabetes melitus tipe II. Pembelajaran menggunakan modul elektronik berbasis problem solving 
lebih kontekstual dan mampu melatih mahasiswa menerapkan dan memanfaatkan ilmu pengetahuan, teknologi, dan seni sesuai bidangnya dalam memecahkan masalah dan beradaptasi. Pembelajaran terintegrasi dengan fenomena kehidupan dapat meningkatkan hasil belajar, pemecahan masalah (Suhartini, Edi, \& Edy, 2016), pemahaman (Ebih, Ratna, \& Yeni, 2015; Santoso, 2017) dan kemampuan berpikir kritis (Ebih et al., 2015; Tantu, 2018).

\section{SIMPULAN}

Hasil validasi ahli media memperoleh persentase $92,74 \%$ yang termasuk kategori sangat valid. Hasil validasi ahli materi memperoleh 91,43\% kategori sangat valid. Hasil validasi praktisi lapangan mendapatkan 93,92\% sangat valid. Hasil uji keterbacaan dan kepraktisan memeroleh presentase sebesar 83,31\% dengan kategori sangat praktis. Modul elektronik berbasis problem solving yang dikembangkan sebaiknya dilakukan uji lebih lanjut untuk mengetahui efektivitas modul elektronik yang dikembangkan.

\section{DAFTAR RUJUKAN}

Aminatun, T., Subali, B., Prihartina, I., F, A. M., Dwiyani, A., Nindiasari, T., Luthfi, M. (2016). Pengembangan Modul Elektronik Berbasis Android Mobile Materi Ekosistem Lokal Nusa Tenggara untuk Meningkatkan Keterampilan Berpikir Mahasiswa SMA. Seminar Nasional Pendidikan Sains . Universitas Sebelas Maret.

Belawati, T. (2003). Pengembangan Bahan Ajar. Jakarta: Universitas Terbuka.

Branch, R. M. (2009). Instructional Design: The ADDIE Approach. London: Springer New York Dordecht Heidelberg.

Carey, G. (2010). Integratif Metabolism: An Interactive Learning Tool for Nutrition, Biochemistry and Physiology. Journal of College Science Teaching, 16-22.

Depdikbud. (2012). Undang-undang RI No. 12 tentang Pendidikan Tinggi. Jakarta.

Ebih, A. R. A., Ratna, R., \& Yeni, H. (2015). Kontribusi Pembelajaran Kontekstual Dengan Teknik SQ4R terhadap Peningkatan Kemampuan Pemahaman dan Berpikir Kritis Matematis. Jurnal Siliwangi, 1(1), 21-31.

Ennis, R. H. (2011). The Nature of Critical Thinking: An Outline of Critical Thinking Dispositions and Abilities. In Emeritus Professor. University of Illinois.

Greenstein, L. (2012). Assessing 21st Century Skills: A Guide to Evaluating Mastery and Authentic Learning. https://uk.sagepub.com/en-gb/asi/assessing-21st-century-skills/book237748\#description

Halidi, H. M., N.H, S., \& Sahrul, S. (2015). Pengaruh Media Pembelajaran Berbasis TIK terhadap Motivasi dan Hasil Belajar IPA Mahasiswa Kelas V SDN Model Terpadu Madani Palu. E-Journal Mitra Sains, 3(1), 53-60.

Krnel, D., \& B. Bajd. (2009). Learning and E-Materials. Acta Didactica Napocensia, 2(1), 97-108.

Magsino, R. . (2014). Enhancing Higher Order Thinking Skills in a Marine Biology Class through Problem-Based Learning. Asia Pacific Journal of Multidisciplinary Research, 2(5), 1-6.

Montagnes, I. (2000). Textbooks and Learning Materials. Dakar, Senegal: World Education Forum.

Pradani, N. C., Zubaidah, S., \& Lestari, U. (2015). Pengaruh Model Pembelajaran Problem Solving Dipadu dengan Jigsaw terhadap Kemampuan Berpikir Kritis dan Hasil Belajar Mahasiswa.

Raharjo, M. W. C., Suryati, \& Khery, Y. (2017). Pengembangan Modul Elektronik Interaktif menggunakan Adobe Flash pada Materi Ikatan Kimia untuk Mendorong Literasi Sains Mahasiswa. Jurnal Ilmiah Pendidikan Kimia "Hydrogen, ” 5(1), 813.

Santoso, E. (2017). Penggunaan Model Pembelajaran Kontekstual untuk Meningkatkan Kemampuan Pemahaman Matematika Siswa Sekolah Dasar. Jurnal Cakrawala Pendas, 3(1), 16-29.

Sarianti, T. M. (2016). Pengaruh Pembelajaran Berbasis TIK terhadap Berpikir Kreatif Mahasiswa pada Materi Sistem Gerak pada Manusia Kelas XI SMAN 2 Kaway XVI Kecamatan Kaway XVI. Journal Bionatural, 3(1), 1-12.

Suarsana, I. M., \& Mahayukti, G. (2013). Pengembangan E-Modul Berorientasi Pemecahan Masalah untuk Meningkatkan Keterampilan Berpikir Kritis Mahasiswa. Jurnal Nasional Pendidikan Teknik Informatika (JANAPATI), 2(3), $193-200$.

Suhartini, I., Edi, S., \& S. Edy. (2016). Pengaruh Pembelajaran Kontekstual terhadap Kemampuan Pemecahan Masalah Matematik dan Kemandirian Belajar Siswa di MTS Miftahussalam Medan. PARADIKMA, 9(3), 62-71.

Sulistyaningkarti, L., Utami, B., \& Haryono. (2016). Penggunaan Model Pembelajaran Problem Solving Dilengkapi LKS untuk Meningkatkan Kemampuan Berpikir Kritis dan Prestasi Belajar Mahasiswa pada Materi Kelarutan dan Hasil Kali Kelarutan Kelas XI SMA Muhammadiyah 1 Karanganyar Tahun Pelajaran 2014/2015. Jurnal Pendidikan Kimia (JPK), 5(2), 1-9.

Tantu, Y. R. . (2018). Penerapan Pembelajaran Kontekstual untuk Meningkatkan Kemampuan Berpikir Kritis Siswa Kelas 11 pada Pelajaran Kimia di UPH College. A Journal of Language, Literature, Culture, and Education POLYGLOT, 14(2), 209-222. 